\title{
Art Education in Lower Secondary Schools in Japan and the United Kingdom
}

This essay compares the system and practice of art education in Japan and the United Kingdom at the lower secondary school level. Three surveys on how art is taught form the basis of this research. I conducted the first survey in 1992, distributed to 156 art teachers in Japan on their "real" curricula and compared them with syllabus samplers of nationally authorized textbooks. From 1993 to 1994, I studied in the United Kingdom the newly introduced National Curriculum and performed a survey on its impact on classroom teaching in 49 art departments in secondary schools, mostly in England. Since 1994, I have participated in a joint study project on craft education in secondary schools in Japan and Britain, in which 717 Japanese schools are cooperating via a questionnaire survey. The issues common to these surveys are how art teachers respond to the national standards in their own teaching practice, and what these responses suggest for the future development of this subject. This essay identifies survey findings in both countries, together with overviews on the systems and cultural factors affecting the state of Art and its implementation in curricula.

\section{Japan and the United Kingdom: An Overview}

Let us look briefly at the historical background of the national curricula in Japan and the United Kingdom. The education system in Japan was established by the central government and has maintained its unity. After World War II, a new national Course of Study was recommended but was not compulsory. But in the legislation of 1958, this Course of Study became binding and a new subject called "Technology and Home Economics" was introduced. A new term, "design" was adopted in Art, "craft" was removed, and the time allocated to Art was drastically reduced. In the 1969 revision, five main areas of Art study were established: drawing (painting), sculpture, design, craft, and art appreciation. In 1977, a recommended time allocation for each area in Art was eliminated, and the five areas were reorganized into two fields: "expression" and "appreciation." Between 1969 and 1977, lower secondary schools in Japan allotted two compulsory hours per week for Art in grades 7 and 8, one compulsory hour and one non-compulsory hour in grade 9. However, after the revisions of 1989 and 1998, the time allotted for Art has gradually decreased. 
In the United Kingdom, different educational systems developed concurrently, and through political and ideological conflicts, the involvement of central government gradually grew until an integrated school system was established. ${ }^{1}$ The National Curriculum, first introduced through the Education Act of 1988, clearly indicates Art as compulsory from Years 1 to 9 in state schools. ${ }^{2}$ The Courses of Study in Japan are separated into primary, lower, and upper secondary levels, however, the consistency of Art as a subject is not as clear. ${ }^{3}$ In England, the content is not differentiated into the areas of art, craft, and design, but is organized as a series of processes common to these areas including investigation, creation, and evaluation, based upon knowledge and understanding.

The United Kingdom has no national system for authorizing textbooks, but the examination board syllabus for the General Certificate of Secondary Education (GCSE), for example, has influenced the school curriculum. Art departments of each secondary school function as fairly independent entities, taking responsibility for curriculum and study resources. In Japan, in most cases, lower and upper secondary schools are separated, with only about one art teacher per school, which means improving the curriculum is determined by the efforts of the individual teacher in a limited environment.

We also need to consider the cultural background. The United Kingdom has made a notable effort to incorporate a multicultural perspective, based upon the urgent recognition that the country has become a multi-ethnic society. There is also a growing awareness in Western societies that individual expression should be approved in relation to the culture of a given social group. In Japan, it has long been pointed out that examples of artworks in textbooks are predominantly of Western origin. ${ }^{4}$ This is because, in the process of modernization, Japan has defined itself in relation to Western culture. However, Courses of Study in recent years require learning about cultures beyond the West and Japan, especially those of Asian countries.

When a British researcher looks at Japanese art classrooms in lower secondary schools using an ethnological approach, the environment and equipment appear very limited. ${ }^{5}$ Compared to the art classrooms in the United Kingdom where the walls are normally filled with reference materials and students' works, Japanese classrooms seem inorganic and factory-like. A large number of students are packed into a uniform box called a classroom, and the lesson is given en masse. The teacher rarely shows artworks or holds discussions on art. Textbooks are rarely used, either. Despite the high overall technical level of the students' work, teachers say that they do not place much emphasis on technical instruction. Teachers claim that the students express their originality, but the source of ideas and thinking processes are not explained sufficiently clearly from the Westerner's logical standpoint.

From the viewpoint of a Japanese researcher, the observed situation of art in British schools is diverse. ${ }^{6}$ Each school has its distinctive characteristics 
which may include: workshops for regular artists in residence, professional photo studios, and stimulating art rooms which look like galleries. Schools may have discipline issues, budgetary limits, and language or cultural barriers. Characteristics common to British art classes include sensitivity to multiculturalism and a free approach to the learning process. For example, along with a report on aboriginal art, students' artworks pertaining to such studies are displayed. When asked, the students will explain how they used sketches to develop ideas leading up to the final work. When asked, the teachers maintain that learning about existing artforms activates the students' free expression, rather than suppresses it. British art education is based on the view that children's development should not be isolated from existing cultures.

\section{Japanese Art Education: Survey Findings (1992)}

There is a tendency to focus on only the centralized character of Japanese education, and consider teaching in schools to be totally under the control of statutory orders. However, Akio Okazaki argues that we should pay more attention to art education beyond the control of government. ${ }^{7}$ I believe that in Art, teachers' discretion and potential to develop their own curricula is relatively open because this subject does not usually figure into entrance examinations, and by nature, is more fluid. Based on this view, I propose that the curriculum made by each art teacher has certain features independent of the national standards and nationally authorized textbooks. By discovering common features, we can describe the art education movement of the time from a new perspective. In 1992, a survey questionnaire was distributed to 294 art teachers in lower secondary schools in 8 districts in Tokyo, with 156 responding. The questions included the content of actual art teaching in the previous year, evaluation of each unit they had taught, and views of teachers and students on each area of study in Art. One distinctive feature of the method was to analyze the time spent on each area of study as well as the views of teachers and students, comparing it with the syllabus sampler in the handbook for teachers (which is not compulsory) attached to nationally authorized textbooks.

Although a detailed analysis is beyond the scope of the present essay, I will note some of the main findings. There was more unification among each teacher's curriculum than expected. Teachers' curricula corresponded with the syllabus sampler in the teacher's handbook of national textbooks on the whole. But there were two significant areas where actual teaching practice diverged from the national textbooks.

First, a complex situation was found in the teaching of drawing. Much less time was spent on drawing than recommended in the syllabus sampler in the handbooks. And the results conflicted between teachers' belief and their teaching practice. The proportion of teachers who are motivated to teach 
drawing and those who find difficulty in teaching this area are both high. "There is motivation in teaching": drawing, $28.8 \%$; sculpture, $10.3 \%$; design (2-D), 23.7\%; craft (mostly 3-D), 30.1\%; art appreciation, $4.5 \%$. "There is difficulty in teaching": drawing, 30.1\%; sculpture, 30.1\%; design (2-D), 3.8\%; craft: $21.2 \%$; art appreciation, $12.2 \%$. On the other hand, students showed less interest in drawing than in any other area. "Areas in which students are not interested": drawing, 46.2\%; sculpture, 10.3\%; design (2-D), 12.2\%; craft, $4.5 \%$; art appreciation, $7.7 \%$; "Areas in which students are interested": drawing, $25.6 \%$; sculpture, $12.2 \%$; design (2-D), $27.6 \%$; craft, $61.5 \%$; art appreciation, $0.6 \%$.

Second, there is a movement toward an emphasis on design (2-D) and craft areas. In addition to the views of the teachers and students mentioned above, there is a clear shift toward design and craft areas in time allocation by the teachers compared with the syllabus sampler in national textbooks. For example, the average percentage of time per year for each area shown in the syllabus sampler for a national textbook is: drawing, $40.5 \%$; sculpture, $11.5 \%$; design (2-D), $20.5 \%$; craft, $15.7 \%$; art appreciation, $12.0 \%$. On the other hand, the average rate of the actual teaching time from the survey results is drawing, $29.1 \%$; sculpture, $9.2 \%$; design (2-D), 30.3\%; craft, $27.1 \%$; art appreciation, $3.6 \%$. According to teachers' written answers, the reasons for this tendency are not limited to study aims such as industrial needs, skill training, and understanding traditional culture, but also include the necessity of keeping order in the classroom. In these units, it is easy to maintain a systematic process. I also assume that the process of designing supports classroom control because it facilitates communication between teacher and students more so than the individual process of self-expression in drawing. Craft is strongly supported by the students, especially woodcraft.

\section{British Art Education: Survey Findings (1994)}

British teachers experienced national control over their teaching for the first time with the introduction of the first National Curriculum of Art in 1992. This presented a unique opportunity for considering the relation between national standards and art teaching practice. Following the initial survey by interviewing art teachers, a questionnaire survey was conducted to investigate the influence of the National Curriculum, the examination board syllabus for GCSE, and critical studies on art teaching in schools. The questionnaire was sent to 102 art departments in secondary schools in the West Midlands in England, with 49 responding.

The Influence of the National Curriculum

First, art in the National Curriculum has broadly influenced the department syllabi of the surveyed schools. Schools changed their art syllabi according to the National Curriculum (71.1\%). The National Curriculum emphasized 
knowledge and understanding of artworks, 77.7\%. There were also clear indications that the National Curriculum affected assessment methods: systematic assessment, 80.0\%; and profiling and coursework assessment, $66.7 \%$. Views on the relation between teaching practice and the National Curriculum were divided.

Influence of the Examination Board Syllabus

The majority of respondents seemed satisfied with the examination board syllabi at GCSE level in several respects: accordance with department syllabus, $97.7 \%$; respect for teacher's decision, $93.4 \%$; respect for student's learning, 95.5\%; criteria for assessment, $84.5 \%$; method of assessment, $82.3 \%$; achievement in the examination: $93.4 \%$. In addition, answers concerning the influence of the examination board syllabus on teaching Key Stage 3 (ages 11 to 14 , which are under the control of the National Curriculum. Usually the curriculum for Key Stage 4, ages 14 to 16, provides the courses for the GCSE examination) were divided.

The Influence of Critical Studies

In art classes, teachers explained artworks using several media: photographic reproductions, 97.8\%; electric media, 75.5\%. Talking about artists' works, 95.6\%; and developing their own works based on the study of artists, $95.6 \%$; seems to be a widely accepted activity for students in critical studies. Teachers appreciate the effect of critical studies on students' progress. They recognized students' improvement in knowledge of art, 88.9\%; interest in art, $73.3 \%$; and skills in making and drawing, 73.3\%.

The Department Syllabus and its Implementation

Painting and drawing, especially observational study, is emphasized in three ways: as a basic skill, as preparation for the examination, and as a starting point for imaginative development. There is also an interest in ceramics and three-dimensional works by both students and teachers although there are difficulties with facilities. Finally, in spite of equipment and knowledge difficulty, there is a strong demand from teachers for the use of computers.

Craft Education in Japan and the United Kingdom: Survey Findings (1994-1995) The survey was conducted under the joint research project between Japanese and British researchers. ${ }^{8}$ We share the view that both countries have internationally recognized craft traditions, but their educational value needs to be reconsidered in the age of emerging technologies. As a starting point for the project, a general survey to determine the nature of craft teaching was taken. In 1994, questionnaires were mailed to Heads of Art (and Design and Technology) Departments in all secondary schools in England and Wales $(5,625)$ resulting in 2,380 returns of which 1,168 came from Art teachers. In Japan, the questionnaires were distributed in 1995 by local education authority 
inspectors to Art teachers and resulted in 717 responses from schools in 45 prefectures. A brief synopsis of the results follows.

First, on the types of craft taught in both countries, indigenous craft is afforded more importance in Japan, while global aspects are emphasized in Britain. Second, the findings on the use of primary and secondary resources to teach craft showed that Japanese schools use much more limited resources except for technical reference materials and textbooks: use of crafts people as primary resources, Britain 20\%, Japan 6\%; museums and galleries, Britain $48 \%$, Japan $18 \%$; use of slides and photos as secondary resources, Britain $79 \%$, Japan $39 \%$; posters and wall charts, Britain $72 \%$, Japan $23 \%$; CD-ROM/multimedia, Britain 30\%, Japan 3\%; technical reference materials, Britain 26\%, Japan $46 \%$.

This essay sheds light on the relation between the national system and teaching practice of Art from survey findings in Japan and Britain. In Japan, based on this comparative study, there is coexistence and conflict between modern values embodied in drawing and traditional values embodied in craft. The former respects individuality and self-expression, while the latter emphasizes community and the spiritual aspect of manual training. It also appears that students have studied hard and produced works of good quality, while there is little consideration for the relation between their learning and the development of the arts and cultures in their society. The limited use of resources in studying art indicates that Japanese schools are culturally isolated. We can now suggest ways to develop the ability to appreciate and criticize art, based on the firm tradition of making, in order to further the culture of the next generation. It can also be concluded that developing research methods for comparative study and inquiry into teaching practice as a dynamic and collective process that enables a new recognition of the current direction of art education.

Toshio Naoe

University of Tsukuba

\section{NOTES}

1. Ronald P. Dore, Gakurekishakai Atarashii Bunmeibyo [The Diploma Disease: Education, Qualification, and Development] trans. Matsui Hiromichi (Tokyo: Iwanami Shoten, 1990), 67-69.

2. It should be noted, however, that in the second half of the nineteenth century, the national system for public art education exerted significant influence. See Stuart Macdonald, The History and Philosophy of Art Education (London: University of London Press, 1970), 188-99. The National Curriculum for England: Art and Design (London: Department for Education and Employment, 1999, online version: <http://www.nc.uk.net>.

3. Shougakkoku Gakushuushidouyouryou [The Courses of Study for Primary Schools] (Japan: Ministry of Education, 1998); Chuugakkoku Gakushuushidouyouryou [The Courses of Study for Lower Secondary Schools] (Japan: Ministry of Education, 
1998); and Koutougakkou Gakushuushidouyouryou [The Courses of Study for Up per Secondary Schools] (Japan: Ministry of Education, 1999). All of these are available online at: <http://www.mext.go.jp>.

4. Murakami Toshifumi and Shimada Hiroshi, "Kokusaisei no Dojou [Bases for Internationalism], in Kyoukasho no Shakaigakuteki Kenkyuu [Sociology of Textbooks], ed. Kataoka Tokuo (Tokyo: Fukumura Shuppan, 1987), 134-57.

5. Rachel Mason, "Artistic Achievement in Japanese Junior High Schools," Art Education 47, no. 1 (January 1994): 8-19.

6. Toshio Naoe, "Nihon to Eikoku: Geijutsu to Kyouiku no Renzokusei wo Megutte [Japan and Britain: Continuity between Art and Education]," in Midoriiro no Taiyo: Hyougen niyoru Gakkou Shinsei no Shinario [The Green Sun: Renovation of Schools thorough Art], ed. Miyawaki Osamu (Tokyo: Kokudosha, 2000), 45-61.

7. Akio Okazaki, "What American Art Educators Learned from the Japanese: A Response to Carson and Dobbs," Art Education 38, no. 4 (July 1985): 6-10.

8. "Anglo-Japanese Research Project: Teaching Craft Heritage" was organized under the leadership of Professor Norihisa Nakase (then University of Tsukuba; Japan) and Professor Rachel Mason (Roehampton Institute; U.K.) in 1994, investigating, comparing, and developing a craft curriculum. 